\title{
Patient Dignity in Iranian Clinical Care Settings as Perceived by Physicians, Caregivers, and Patients
}

This article was published in the following Dove Press journal:

Journal of Multidisciplinary Healthcare

\author{
Banafsheh Tehranineshat (ID ${ }^{\prime}$ \\ Mahnaz Rakhshan (D) \\ Camellia Torabizadeh (iD ${ }^{\prime}$ \\ Mohammad Fararouei ${ }^{2}$ \\ 'Community Based Psychiatric Care \\ Research Center, Department of \\ Nursing, School of Nursing and \\ Midwifery, Shiraz University of Medical \\ Sciences, Shiraz, Iran; ${ }^{2}$ Department of \\ Epidemiology, Shiraz University of \\ Medical Sciences, Shiraz, Iran
}

Introduction: All over the world, healthcare team members are recommended to respect patients' human dignity. However, the dignity of hospitalized patients is not preserved in many cases. Due to the abstract, complex, and cultural nature of the concept of human dignity, further studies are required to precisely determine the different aspects of this concept.

Purpose: The aim of the present study was to explore the experiences and perceptions of physicians, nurses, family caregivers, and hospitalized patients with regard to patient dignity in Iranian clinical setting.

Materials and Methods: This is a qualitative, exploratory study in which physicians, nurses, family caregivers, and patients were recruited from 2 educational hospitals located in an urban area in Iran from April 2016 to February 2017 using the purposive sampling method $(\mathrm{n}=24)$. Data were collected through individual interviews and subsequently analyzed using conventional content analysis in the software MAXQDA 2007, VERBI ${ }^{\mathrm{O}}$.

Results: Three major themes emerged from analyses of the data obtained from the interviews: a peaceful environment, respect, and comprehensive support.

Conclusion: From the participants' point of view, in order for their dignity to be preserved, patients need to be hospitalized in a peaceful environment in which they are treated with empathy, they receive comprehensive support, and the care settings are managed properly. Furthermore, it is important to respect patient's values and beliefs, to provide unbiased care and treatment, and to maintain patient's autonomy in order to maintain hospitalized patients' dignity.

Keywords: dignity, respect, physician, healthcare providers, nurse, family caregiver, patient, health care ethics

\section{Introduction}

Human dignity, as an ethical value, is a key concept in medical ethics. Preservation of human dignity has been emphasized as a moral obligation of healthcare providers all over the world. ${ }^{1}$ Medical ethics require that physicians should be polite to patients, maintain patients' privacy, and respect their beliefs and values. ${ }^{2}$ Preserving patients' dignity is also an essential element in the nursing code of ethics. ${ }^{3}$

There are two kinds of dignity: basic dignity and relative dignity. Basic or universal human dignity is the dignity which all human beings possess as humans. ${ }^{4}$ Relative dignity concerns an individual's social status and can be acquired or lost. ${ }^{5}$ Social dignity is alternatively known as dignity of identity. This kind of dignity is related to dignity-of-self, self-respect, and respect for others. There is a significant relationship between dignity of identity and sickness and hospitalization as sickness
Correspondence: Mahnaz Rakhshan Research Center, Department of Nursing, School of Nursing and Midwifery, Shiraz University of Medical Sciences, Zand St., Nemazee Sq, 7193613119, Shiraz, Iran Email mzrakhshan@gmail.com 
can undermine individuals' independence and pose a threat to their personal identity, which, in turn, adversely affects their dignity. ${ }^{6}$ In hospitals, patients meet unfamiliar people, have to abandon their personal and social daily activities and roles, and are expected to perform tasks set for them by the medical staff, all of which factors lead to patients' developing new needs and facing the risk of losing their dignity. ${ }^{7}$

Studying 10 elderly patients and 10 family caregivers in Finland, Koskenniem \& Leino-kilpi (2012) report that nurses' behaviors and responsiveness to patients' needs determine the degree to which patients feel that their dignity is maintained. ${ }^{8}$ Lohne et al (2014) have studied family caregivers' experiences of patient dignity in nursing homes in Scandinavian countries. The themes the researchers extracted from the interviews were "treating others as you are treated by them" and "lack of peace due to loss of dignity." Based on the experiences of the interviewed family caregivers, patient dignity is a function of respect, trust, security and charity. ${ }^{9}$ According to the study of Bagheri et al (2012), maintaining patients' dignity contributes to patients' self-esteem, stress-relief, satisfaction with their care, and feeling respected. ${ }^{10}$ On the other hand, disrespect for patients' dignity can create feelings of insecurity, inferiority, and shame in patients, which, in turn, lengthens patients' hospital stay. ${ }^{11}$

Dignity is also an important component of quality of life, especially in nursing homes. ${ }^{12}$ The results of the study of Kisvetrova et al (2019) in Czech Republic show that depression and dignity are predictors of quality of life and perception of the elderly with and without dementia. ${ }^{12}$ In their study of cancer patients in Iran, Hosseini et al (2017) conclude that there is a significant, positive relationship between dignity and quality of life: an enhanced sense of dignity in end-stage cancer patients improves patients' symptoms and performance. ${ }^{13}$

Maintaining patients' dignity is essential to highquality healthcare. ${ }^{14}$ According to the study of Baillie (2009) in the 22-bed surgery department of a hospice in England, patients' health status, immediate environment, and caregivers' behaviors have an impact on patients' dignity. ${ }^{15}$ In the study of Gastmans et al (2013) in Belgium, the patients referred to such behaviors as ignoring, despising, and prejudging patients as signs of disrespect for human dignity. ${ }^{16}$ The results of the study of Papastavrou et al (2014) in Cyprus show that personal factors can put patients' dignity at risk. These factors, which occur in the interpersonal relationships between patients and nurses in hospitals, include disregard for patients' preferences, verbal abuse, failure to regard the patient as a unique being, failure to maintain patients' confidentiality and privacy, lack of autonomy, and discrimination. ${ }^{17}$ According to the study of Rehnsfeldt et al (2014) conducted in Denmark, Sudan, and Norway, healthcare services based on routine care plans and procedures are symptoms of poor healthcare and disregard for patient dignity in a culture. ${ }^{18}$

The study of Ebrahimi et al (2012) in Iran shows that the majority of patients are dissatisfied with their ineffective interactions with doctors and nurses and consider such issues as lack of equipment and facilities in hospitals, eg, inadequate blankets and bed covers, unhygienic conditions, annoying sounds in the wards, and the discomfort of their companions as indicators of disrespect for patient dignity. ${ }^{19}$ In the study of Naderi et al (2019) in Iran, some of the in-patients considered their experiences of being objectified, disdainful behaviors, disregard for their preferences in treatment, and insufficient verbal and nonverbal communications as examples of violation of their dignity. $^{20}$

Many studies have evaluated human dignity from the perspective of nurses and patients. ${ }^{21-23}$ Nevertheless, only a limited number of studies have focused on the concept of dignity from the perspective of physicians and family caregivers. Though nurses' perception of patient dignity has been investigated, ${ }^{22}$ physicians have a different perception of patients' needs due to their different professional role, resulting in their setting distinct treatment goals for patients. On the other hand, family caregivers play a key role in medical centers in Iran. They are in close contact with the patients and provide the medicines and medical equipment which are unavailable in hospitals. Since dignity is highly dependent on physical environments, organizational culture, and inter-professional interactions, ${ }^{19}$ the viewpoints of physicians and family caregivers on dignity should be considered to obtain more precise information on the concept of patient dignity.

Patient dignity is a complex and multidimensional concept and a function of cultural and social factors. ${ }^{6}$ A qualitative study can allow for a deeper understanding of this concept and better determination of its dimensions by giving access to the perspectives of people from different roles and cultural backgrounds who have been engaged with the concept in question for long periods. ${ }^{24}$ The researchers hope that the results of the present research will help managers and health professionals to provide 
a supportive and empowering environment where the dignity of patients is maintained. The aim of the study is to establish the various dimensions of patient dignity as perceived by physicians, nurses, family caregivers and hospitalized patients.

\section{Materials and Methods}

In the present study, patient dignity was evaluated from the perspectives of physicians, nurses, family caregivers and hospitalized patients. A total of 4 physicians, 6 clinical nurses, 6 patients, and 8 family caregivers from 2 major educational hospitals affiliated with Shiraz University of Medical Sciences were selected using purposive sampling. The study lasted from April 2016 to February 2017. The participants were people with specific experience or knowledge of the study subject. ${ }^{25}$ Sampling continued until full data saturation had been achieved. During the study, participants were selected based on the required variation in sample and the progress of the interviews.

The inclusion criteria were: at least a general practitioner's degree for the physicians, a bachelor's degree for the nurses, being willing to participate, being mentally and physically prepared for an interview, giving written informed consent for an interview, being Iranian, being able to speak Persian, and not being fatigued due to work overload.

The inclusion criteria for the family caregivers were: being a family member or relative of the patient, being aged over 18 years, having direct contact with the patient, and being considered as a family caregiver by the patient. With regard to the patients, those who were aged over 18 years and had been hospitalized for at least three days were recruited into the study. All the participating patients and family caregivers were Iranian, spoke Persian, were mentally and physically fit to be interviewed for at least 45 minutes, had given written informed consent for an interview, and were willing to participate in the study. The subjects who had a known mental or metabolic disorder, were on medication which had an impact on the mind, and were mentally or physically fatigued were excluded.

Data were collected through semi-structured, in-depth, individual interviews. Overall, the first author conducted 26 face-to-face interviews with 24 participants. Each of the nurses, patients, and family caregivers was interviewed once; two of the doctors were interviewed twice, and the other two (doctors) were interviewed once.

All the participants were asked to give their informed consent before being interviewed. The interviews were conducted in appropriate locations in the hospitals with prior arrangement with the participants. Each interview lasted for 45-60 minutes. The participants who were not willing to be interviewed again were excluded from the study. Each interview started with a general question"what does patient dignity mean to you?"- followed by more specific questions, including "What are your experiences of having had your dignity preserved or ignored during your hospital stay?", "Under what conditions will your dignity be preserved?", "How do you feel when your dignity is not respected?" (for patients), "what are your experiences of maintaining or disrespecting your patients' dignity?", "what do you do to preserve your patients' dignity during your shifts?", and "Under what conditions will your patients' dignity be preserved or put at risk?' (for physicians, nurses, and family caregivers). Next, follow-up questions-"please give an example?", "What do you mean?"-were asked.

The present qualitative study was conducted using conventional content analysis. This method is widely used for exploring rich and new data and mental analysis of the content of textual data through a systematic process of classification, codification and theme making. ${ }^{26}$ In the present study, the conventional content analysis method proposed by Graneheim and Lundman (2004) was applied. $^{27}$ Accordingly, immediately after each interview, the first author (BT) transcribed the recorded interview and read and reread the transcript and, after getting a general idea of the content, applied the inductive method of data analysis. Significant paragraphs in the transcripts were marked to be distinguishable from the other parts. The words, sentences, or paragraphs which carried significance with regard to patient dignity were set as semantic units. Every important paragraph or phrase was assigned a code. Subsequently, the second author (MR) reviewed the transcripts and verified the semantic units and open codes. Possible disagreements regarding the semantic units and codes and the quality of data analysis were addressed in meetings attended by all the members of the research team (BT, MR, CT, MF). Based on the differences and similarities among the codes, the classification and development of categories were continued. The reliability of the codes was confirmed through a review of the categories in the context of the data. After careful and indepth contemplation of the categories and comparing them with each other in several meetings, the research team extracted the themes. The data were analyzed using MAXQDA software 10. 0R250412 (developed and 
distributed by VERBI Software Company in Berlin, Germany).

The criteria of Lincoln and Guba (1985) were used to ensure the accuracy of the collected data. ${ }^{28}$ For credibility, the researchers applied long-term engagement with data (11 months), member checking and peer debriefing, subject triangulation (physicians, nurses, patients, and family caregivers in various gender and age groups), time triangulation (data collection in different work shifts), place triangulation (different departments and different hospitals), maximum variation in sampling, and searching for contrasting evidence. As for dependability and confirmability, the researchers used an audit trail of the accuracy of the interview techniques and data analysis. Transferability was ensured through a complete description of the categories, the characteristics of the participants, and the methods of data collection and analysis.

\section{Results}

A total of 4 physicians, 6 nurses, 6 hospitalized patients, and 8 family caregivers participated in this study. Three major themes emerged from the analyses of data obtained from the interviews, namely a peaceful environment, respect, and comprehensive support (Table 1).

\section{Peaceful Environment}

The findings of the study revealed that a peaceful environment was one of the most prominent aspects of human

Table I The Themes and Categories Extracted from Analysis of Data $(\mathrm{N}=24)$

\begin{tabular}{|c|c|}
\hline Themes & Category \\
\hline \multirow{2}{*}{$\begin{array}{l}\text { Peaceful } \\
\text { environment }\end{array}$} & Empathy \\
\hline & Management of clinical settings \\
\hline \multirow[t]{5}{*}{ Respect } & Respect for human identity \\
\hline & Respect for patient privacy \\
\hline & Respect for patients' beliefs and values \\
\hline & Involvement of patients in decision-making \\
\hline & Unbiased treatment \\
\hline \multirow{3}{*}{$\begin{array}{l}\text { Comprehensive } \\
\text { support }\end{array}$} & Healthcare information support \\
\hline & $\begin{array}{l}\text { Psychological support for patients and family } \\
\text { caregivers }\end{array}$ \\
\hline & Social support \\
\hline
\end{tabular}

dignity from the perspective of all the participants. Based on the experiences of the nurses, physicians, patients, and family caregivers, preservation of patient dignity depends on expressions of kindness, effective caregiver-patient communication, effective use of communication skills, and effective management of clinical settings. In such an environment where their needs are taken into consideration, patients and their family caregivers feel comfortable and valued. The categories of the theme of peaceful environment are empathy and management of clinical settings.

\section{Empathy}

From the perspective of the doctors and nurses in the present study, sharing emotions, approaching the patients emotionally, and creating an emotional bond with patients during treatment and care contribute to maintaining patient dignity.

Intimacy, expressions of kindness, and caring are part of proper physician/nurse-patient and physician/nursefamily caregiver communications. Doctors' and nurses' understanding behaviors and actions can show empathy and compassion toward patients and relieve the worries of patients and their family caregivers, resulting in maintenance of patients' dignity. From the patients' point of view, non-verbal communications are an integral part of maintaining human dignity in in-patient care and treatment and reflect the feelings and attitudes of doctors and nurses toward patients. One of the patients described the conditions which made him feel valued as follows:

Some doctors smile at me ... joke with me and call me by my first name when they come to visit me. This makes me feel valued ... and makes me feel at home and I can communicate with them very easily ... (Patient, 24 years old).

From the physicians' viewpoint, physicians and nurses should use appropriate verbal techniques in their communications with patients to understand and identify with their problems and make them feel more comfortable. This reflects respect for patients' dignity. A Physician said:

Once, I had an Arabic patient ... I learned a few Arabic words from his companion and tried to use these words when communicating with the patient because I thought using a common language would help me understand the patient better and make the patient feel more comfortable ... (Physician, 36 years old).

The physicians also believed that physicians and nurses should share feelings and show empathy to properly perceive and identify with the feelings of their patients in 
order to be able to take appropriate action to resolve patients' problems and concerns.

When a physician imagines himself or herself in a patient's position or as a family member of the patient, he or she may better understand the patient's problems ... (Physician, 28 years old).

\section{Management of Clinical Settings}

The nurses in the present study referred to proper ventilation, hygiene, and noise reduction devices as important factors associated with the preservation of patient dignity.

At night, we reduce the volume of the alarms. Also, we put a folded bed sheet behind the door so that the sound of the door opening does not disturb the patients' comfort ... (Nurse, 42 years old).

Some of the patients and family caregivers compared their situation to being held as prisoners in the hospital and stated that lack of decoration, poor hygiene, and inadequate space for the entertainment of the hospitalized patients indicated disregard for the human dignity of the patients. They expected the hospital environment to be happier and more home-like. Some of the caregivers acknowledged that, although they expected the patients to have a companion at the time of admission, the hygienic conditions, toilet facilities, supplies of bed sheets and blankets, and beds were inadequate for the family caregivers.

The family caregivers stated that the complex admission process caused them to frequently ask the management and supervisors to move their patients to the main ward, which may have wasted the time of the patients and family caregivers and adversely affected the treatment process.

According to one of the family caregivers:

We were in the emergency department for several days. It was very crowded and noisy. Every time I took my patient away for sonography tests, her bed would get occupied and they would take the chairs too .... When I told the personnel there were no empty beds, they would tell me to wait for a patient to leave and take their bed ... we had so much trouble there .... It was a week before we could enter the main ward and my patient was exhausted and frustrated by then ... (Family caregiver, 36 years old).

Some of the caregivers referred to delays in the implementation of medical procedures and incorrect triage as a threat to their dignity.

My patient's been in the internal ward for 16 days waiting for her turn to do ERCP. They give her morphine and painkiller injections every day. She has to be NPO from midnight until noon and then they say the operation has been cancelled. Her condition has gotten worse since we came here .... Patient dignity can be maintained only when clinical measures are performed without delay ... (Family caregiver, 42 years old).

\section{Respect}

According to the experiences of the nurses and patients, showing respect for patients' identity, humanity, and protection of privacy are essential for the preservation of patient dignity. These are key ethical values that the medical personnel should consider when they provide care to patients and interact with their family caregivers. Furthermore, consideration of patient identity, equity, and justice as patient rights in healthcare were considered to be necessary for patient dignity to be preserved from the viewpoint of the study participants. The categories of respect for human identity, respect for patient privacy, respect for patients' beliefs and values, involvement of patients in decision-making, and unbiased care form the theme of respect.

\section{Respect for Human Identity}

The experiences of the nurses suggested that showing respect for patients' identity, avoiding degrading behaviors, and exercising courtesy in the process of providing care are essential to maintaining patient dignity.

Treatment and care must be accompanied by respect. When a patient is hospitalized and needs treatment, we should not forget that this patient may be a father, mother, grandfather, or grandmother who is treated with respect in his or her own family... (Nurse, 35 years old).

Also, objectification of patients was identified as another serious threat to patients' human dignity.

Sometimes, they just act like robots; they quickly do something for the patient and then leave ... patients have emotions and feelings, and such behaviors make them feel worthless ... (Patient, 46 years old).

\section{Respect for Patient Privacy}

All the participants believed that maintaining patients' privacy was ethical and that the treatment team members must respect patients' privacy under any conditions. Respect for patient privacy refers to medical personnel's treating patients' information as confidential during their hospitalization period. Patient privacy emphasizes avoidance of revealing patients' information. The nurses considered appropriate covering of patients' bodies as one of 
the aspects of preserving patient dignity and believed that, as part of their personal space, patients' bodies must be treated with respect.

A woman had returned from the operating room. It was visiting hours. We pulled the curtains aside to let her family see their patient. Because of the arterial line, the patient's arm was exposed. Her family asked me to cover their mother's arm with something ... (Nurse, 29 years old).

With regard to maintaining patients' privacy toward maintaining their dignity, one of the nurses stated that:

Patients who are brought out of the operating room are not conscious and will not know if their bodies are exposed. But we try to keep them properly covered ... (nurse, 44 years old).

From the doctors' perspective, maintaining patient confidentiality is another important aspect of dignity-based care. Sometimes, breach of confidentiality can exacerbate patients' current conditions. Patient confidentiality is stressed by medical ethics and patient rights charters. In this regard, a female doctor with 5 years' work experience stated that:

We must definitely keep our patients' secrets .... For example, once I had a patient who was addicted to opium. He insisted that he did not want his wife to know .... We took care to keep his addiction secret and I told all the staff to do the same thing ... (Physician, 33 years old).

On a similar note, a patient mentioned that:

My wife's family tried hard to find out about my condition through my doctor. However, my doctor expressly told them that my information was confidential .. . (patient, 34 years old).

Being cared for by an opposite-sex caregiver can seriously threaten patients' dignity. Also, the family caregivers stated that the presence of other patients' companions and opposite-sex personnel was a threat to patient dignity.

My mother had wounds on her legs ... but sometimes her wound dressing was changed by a male nurse .... My mother was very embarrassed by this and felt that the treatment team did not value her because they did not care about her privacy... (Family caregiver, 38 years old).

\section{Respect for Patients' Beliefs and Values}

From the nurses' viewpoint, respect for patients' beliefs, values, and thoughts reflect the preservation of their human dignity. They believed that the treatment team members could preserve the patients' dignity by respecting their beliefs and values as they provided care to them.
I once had a Christian patient and we had no Bibles in the ward. One of the archiving staff was a Christian. I managed to get a Bible from him and gave it to my patient ... (Nurse, 48 years old).

Similarly, the doctors who participated in the study stated that, out of respect for the patients' dignity, they used expressions and phrases which were consistent with the patients' religious beliefs during the examination and treatment processes to help them heal more quickly.

During treatment, we tell our patients and their families that we will try our best but they should place their trust in God ... (Physician, 33 years old).

\section{Involvement of Patients in Decision-Making}

The patients believed that, in order for patient dignity to be preserved, patients and their family caregivers should be allowed to participate in the making of decisions around their treatment plans and procedures. Some of the participants stated that their dignity was disrespected as they were not informed about their treatment plans. Some others expressed that they desired to have the right to choose their doctors or nurses.

It is important that they ask me about my opinion ... I have the right to participate in my treatment process ... (Patient, 32 years old).

In the present study, the doctors and nurses tried to have the patients and their family caregivers actively participate in their treatment by providing them with the necessary information.

I always explain the meaning of surgical consent to my patients and their companions. I tell them that the information is not meant to make them worried and they should not think that they are definitely going to have the complications mentioned in the forms. I explain that it is my duty to inform them about surgical complications. And that it is up to them to accept the risks or not ... (Nurse, 37 years old).

\section{Unbiased Treatment}

Treating patients of any ethnicity, race, or nationality based on equity was described as a prominent example of respect for patient dignity by the doctors in the present study. Also, the experiences of the doctors indicated that patient dignity was violated through some patients' unfair access to facilities and medical equipment which were unavailable to other patients.

Some of the patients here are Turk or Lur or from other ethnic minorities ... but it does not make any difference to us; we provide equal care to all patients ... (doctor, 33 years old). 


\section{Comprehensive Support}

In the present study, comprehensive support was found to consist of healthcare information support, psychological support for patients and family caregivers, and social support.

\section{Healthcare Information Support}

The majority of the patients and family caregivers stated that being provided with insufficient information adversely affected their sense of dignity. Patients and family caregivers expect the medical personnel to provide them with clear and complete information regarding different treatment methods and patients' medical status and laboratory test results. According to the results of the study, patients and family caregivers regard doctors' and nurses' failure to inform them properly as a threat to the dignity of patients and family caregivers.

The experiences of the patients and family caregivers showed that raising the awareness of the patients or their families by introducing them to the patients' conditions, the patients' degree of preparation for treatment, and the necessary medical instructions was a sign of respect for patient dignity.

The family caregivers claimed that their dignity was violated when they were told to stay outside during the doctors' visits and were not informed of their patients' treatment plans.

According to one of the family caregivers:

When the doctors are on their rounds, I must be present by my mother's side so that I can explain her problems to the treatment team and ask my mother's doctor about the progress of her disease and the different methods of treating her (Family caregiver, 48 years old).

\section{Psychological Support for Patients and Family Caregivers}

From the perspective of the hospitalized patients and their family caregivers, being diagnosed with a disease, treatment procedures, and even follow-up care affect patients deeply. Patients and their family caregivers experience high levels of stress and psychological tension; thus it is necessary that the sources of their stress be identified and they be provided with proper counseling services to be able to adjust to their current conditions and feel that their dignity is valued.

My patient's spirits are really low .... My nephew had the same medical condition and died. Ever since then, my mother has been so desperate. She seriously needs counseling. I myself have started to hate life. The stress of diseases and treatments can put you under so much pressure ... (Family caregiver, 34 years old).

With regard to caring about the emotional needs of family caregivers, one of the nurses said:

The sudden death of one of the heart patients here caused her daughter to get depressed .... I met here when her mother was hospitalized here .... To help her recover emotionally, I introduced her to a counselor. I sometimes took her myself ... (nurse, 38 years old).

\section{Social Support}

The family caregivers stated that, in addition to the distress caused by their patients' health conditions, their inability to buy certain medications and high hospital costs put them under extra pressure and forced them to seek financial help from relatives or friends due to lack of money and social support organizations, which undermined their dignity. By introducing the patients who were in need of financial support to charities and raising funds in the hospital for them, the members of treatment teams tried to reduce the concerns of the patients and their family caregivers and maintain their dignity.

We have put a charity box in the break room to maintain the patients' dignity. All the personnel, even the students, donate by putting some money in the box. The money is used to help the patients who need it ... (Nurse, 35 years old).

\section{Discussion}

Three major themes emerged from analyses of the data: peaceful environment, respect, and comprehensive support. Based on the experiences of the study participants, creating a comfortable environment and establishing an empathetic relationship with hospitalized patients contribute to maintaining the human dignity of patients and their family caregivers. Also, for patient dignity to be maintained, professional care providers should respect the humanity of patients, respect their identity, privacy, values, and beliefs, avoid discrimination, respect patient autonomy, and pay attention to the various aspects of patients' existence.

According to the results of the study, understanding the patients' emotions through effective communication skills, keeping the hospital environment hygienic, and facilitating patient admission reflect respect for patient dignity. The importance of empathy in doctor-patient relationships has been repeatedly emphasized in medical research. ${ }^{29,30}$ 
Shafati and Zahedi (2013) report that doctors cannot fully understand their patients without entering their personal world through empathy. ${ }^{31}$ When a doctor is aware of a patient's true emotional status, he or she can distinguish between the physical and psychological causes of the patient's problems. ${ }^{32}$ According to the literature, communicating with patients in an intimate and friendly way can help with discovering the patients' feelings and resolving their problems. ${ }^{33}$ According to Manookian et al (2014), patient dignity is preserved through an attempt to understand patients' emotions, listening to their concerns, and a desire to help them overcome their problems. Showing respect for patients' human dignity during care involves being kind, empathetic, and compassionate to patients. ${ }^{11}$ The results of the study of Hosseini et al (2017) about the dignity and quality of life of end-stage cancer patients in Iran show that when patients are treated in a friendly manner, they have more peace, hope, and trust.

Most of the patients and family caregivers in the present study considered satisfactory hospital equipment and facilities as a key element in maintaining patient dignity. Some of the participants stated that their dignity was violated by unhygienic conditions and loud noises in their environment. The results of several studies in Iran and other parts of the world support these findings. ${ }^{20,34-37}$ In a similar study, a better physical environment, facilities, greenery in the hospital, and silence are listed as contributors to preservation of patient dignity. ${ }^{19,34}$

According to the findings of the present study, respect is another theme of patient dignity. From the perspective of the medical staff, respect for patients' identity was one of the important aspects of ethical care. ${ }^{12}$ Other studies have similarly stressed the importance of showing respect for patients' identity, ${ }^{38-40}$ which includes respect for age and religious identity and avoidance of pity and discriminatory behaviors, in maintaining human dignity. ${ }^{40,41}$ In Matiti and Trorey's study (2008), justice in care, ie, providing equal access to healthcare services and meeting patients' needs based on their cultural differences, is the most important component of professional values. ${ }^{35}$ Respect for dignity is manifested by hospital staff's acceptance of equal human rights, considering each patient as a unique human being, and focusing on patients' internal values, regardless of their age, gender, race, and religion. ${ }^{42}$

Another theme identified for dignity was involvement of patients and their family members in decision-making. According to Baillie and Matiti (2013), patient autonomy is one of the main aspects of preservation of human identity and is a fundamental principle in ethical and patient-centered care. ${ }^{43}$ Papastavrou et al (2016) state that patient dignity is preserved when patients are allowed to participate in the setting of their treatment plans. ${ }^{17} \mathrm{Lin}$ et al (2013) report that the participation of patients' families in empowering and motivating patients and patients' participation in peer groups are crucial to the success of treatment. ${ }^{44}$ According to the results of study by Christensen and Hewitt-Taylor (2007), patient empowerment requires a proper balance of power between the patient and healthcare provider. In other words, the most effective strategy to minimize paternalism is to focus on behaviors which facilitate patients' empowerment. ${ }^{45}$

From the participants' point of view, respecting the beliefs and values of patients and their family caregivers was an important aspect of maintaining patient dignity, which is consistent with the results of other studies. A study reports that the significance of respect to Iranian patients is rooted in their religious beliefs. ${ }^{46}$ Other international studies emphasize that showing consideration for patients' major beliefs positively affects maintenance of their dignity. ${ }^{41,42,44}$ Therefore, it is important to pay attention to patients' expectations and values to maintain their dignity. ${ }^{47,48}$

The results of the present study revealed comprehensive support as another theme of dignity. Informational support is defined as the provision of sufficient information to patients and family caregivers so that they can more easily manage stressful situations and adopt effective coping strategies. ${ }^{49}$ Informational support is not only a moral duty to patients and their companions, but is regarded by them as a value expected of nurses and doctors. ${ }^{50}$ Stahl and Tomlinson (2017) claim that the right to know about one's illness is one of the most obvious rights of a patient.${ }^{51}$ Therefore, any information provided based on patients' needs will contribute to the preservation of their autonomy and dignity. ${ }^{52}$ Patients and their family members expect to receive information regarding their care plans because they want to have the opportunity to make informed decisions. ${ }^{53}$ Only a limited number of studies have been conducted on the impact of family and its support on patient dignity. In the Iranian culture, family plays an important role in supporting the patient. The companionship of family members in the hospital and visits from relatives and acquaintances are a part of social and religious values in Iran. In such a culture, holistic healthcare demands the medical personnel's attention to the needs of patients and their family members. ${ }^{54}$ 
The participants of the present study believed that, in addition to patient's physical and social needs, the emotional and psychological needs of patients' families should be taken into account. Babaei et al (2016) describe holistic care as showing attention to the needs of patients and their family members. ${ }^{55}$ In a review study in Australia, Kornhaber et al (2016) list therapeutic listening, responsiveness to patients' emotions and needs, and patient-centered care as essential to improving clinical inter-personal relationships. ${ }^{56}$ The study of Fan et al (2017) in Taiwan shows that the medical personnel should act as a mediator between patients and their family members to facilitate their relationship and resolve their conflicts. By supporting patients and their family caregivers, the medical personnel can help them cope with stress. ${ }^{57}$

Davidson (2009) names the need for information as the most important psychological and social need of patients' families and states that the informational support of the medical personnel in their relationship with patients' family members is an effective way to facilitate their adjustment. $^{58}$

Social support, as another subcategory of comprehensive support, can be realized through the financial support and assistance of state support organizations and NGOs. The results of a study show a positive relationship between social support and health. ${ }^{59}$ In an integrative review study by Chaudhary and Sharma (2019), financial support through donations from government agencies and charity organizations is reported to be an essential factor in maintaining patients' human dignity. ${ }^{60}$ Also, social support is one of the contributors to preservation of human dignity in the model of dignity-conserving care proposed by Chochinov (2002). When patients are acknowledged by the society and are valued and treated with respect, only then can patient dignity be maintained. ${ }^{61}$

\section{Limitations}

One of the limitations of the present study is the small size of the sample. The findings of the study do not specify the exact source of each theme and category extracted from the experiences of the patients, family caregivers, nurses, and doctors. Also, the views of other healthcare professionals are not included. In addition, data were collected exclusively via individual interviews and in the educational hospitals in the south-east of Iran. Accordingly, it is recommended that, in order to collect richer information, future studies incorporate the views and experiences of other healthcare professionals such as physician assistant, physiotherapist, psychologist, emotional, social and spiritual support providers selected from a wider range of medical centers. It is also recommended that different healthcare professionals, family caregivers, and hospitalized patients be interviewed about patient dignity in focus group interviews.

The findings of the study can be employed in medical and nursing systems, eg, research, education, and practice, especially in the field of professional ethics. The findings can also prove useful to healthcare policy-makers, managers, and care providers in bridging the gap between values and practice and the gap between theory and practice.

\section{Conclusions}

Respect for patient dignity is one of the most important aspects of care in hospital settings. According to the results of the present study, treating patients with empathy, providing a comfortable physical environment, showing respect for patients' privacy, beliefs and values, involving patients in decision-makings, providing unbiased care, informing patients about treatment procedures, and giving psychological and social support contribute to the preservation of patient dignity in hospitals. Doctors and nurses are expected to maintain patient dignity in compliance with healthcare code of ethics and to improve the quality of care.

\section{Ethics Approval and Consent to Participate}

This study was conducted in accordance with the Declaration of Helsinki. The present study has been approved by the Research Ethics Committee of Shiraz University of Medical Sciences, Shiraz, Iran (Code: IR. SUMS.REC. 1396.S197). Before each interview, the participants were informed about the objectives of the study, confidentiality, reasons for recording the interviews, and the role of the interviewer/researcher. Written informed consent was obtained from all the participants.

\section{Acknowledgments}

The authors would like to express their deep gratitude to the doctors, nurses, family caregivers, and patients who participated in the study, as well as the authorities of the hospitals where the study was conducted.

\section{Author Contributions}

All authors made substantial contributions to conception and design, acquisition of data, or analysis and interpretation of 
data; took part in drafting the article or revising it critically for important intellectual content; agreed to submit to the current journal; gave final approval of the version to be published; and agree to be accountable for all aspects of the work.

\section{Funding}

There is no funding to report.

\section{Disclosure}

The authors declare no potential conflicts of interest regarding the research, authorship, this work, or publication of the article.

\section{References}

1. Kadivar M, Mardani-Hamooleh M, Kouhnavard M. Concept analysis of human dignity in patient care: rodgers' evolutionary approach. $J$ Med Ethics Hist Med. 2018;11.

2. Zaidi S. Ethics in Medicine. Cham; Heidelberg; New York; Dordrecht; London: Springer; 2013:164.

3. Lin YP, Tsai YF. Maintaining patients' dignity during clinical care: a qualitative interview study. $J$ Adv Nurs. 2011;67:340-348. doi:10.1111/j.1365-2648.2010.05498

4. Jacobson N. Dignity and health: a review. Soc Sci Med. 2007;64 (2):292-302. doi:10.1016/j.socscimed.2006.08.039.

5. Sagbakken M, Nåden D, Ulstein I, Kvaal K, Langhammer B, Rognstad MK. Dignity in people with frontotemporal dementia and similar disorders - a qualitative study of the perspective of family caregivers. BMC Health Serv Res. 2017;17(1):1. doi:10.1186/s12913017-2378-x

6. Bidabadi FS, Yazdannik A, Zargham-Boroujeni A. Patient's dignity in intensive care unit: A critical ethnography. Nurse Ethics. 2017;1-15. doi:10.1177/0969733017720826.

7. Oosterveld-Vlug MG, Onwuteaka-Philipsen BD, Pasman HR, van Gennip IE, de Vet HC. Can personal dignity be assessed by others? A survey study comparing nursing home residents' with family members' nurses' and physicians' answers on the MIDAM-LTC. Int J Nurs Stud. 2015;52:555-567. doi:10.1016/j.ijnurstu.2014.06.007.

8. Koskenniem J, Leino-Kilpi HS, Suhonen R. Respect in the care of older patients in acute hospitals. Nurs Ethics. 2012;20(1):5-17. doi:10.1177/0969733012454449.

9. Lohne V, Rehnsfeldt A, Råholm MB, et al. Family caregivers' experiences in nursing homes: narratives on human dignity and uneasiness. Res Gerontol Nurs. 2014;7(6):265-272. doi:10.3928/ 19404921-20140325-99

10. Bagheri H, Yaghmaei F, Ashktorab T, Zayeri F. Patient dignity and its related factors in heart failure patients. Nurs Ethics. 2012;19 (3):316-327. doi:10.1177/0969733011425970

11. Manookian A, Cheraghi MA, Nasrabadi AN. Factors influencing patients' dignity: a qualitative study. Nurs Ethics. 2014;21 (3):323-334. doi:10.1177/0969733013498526

12. Kisvetrova H, Herzig R, Bretsnajdrova M, Tomanova J, Langova K, Skoloudik D. Predictors of quality of life and attitude to ageing in older adults with and without dementia. Aging Ment Health. 2019;23:1-8. doi:10.1080/13607863.2019.1705758.

13. Hosseini A, Rezaei M, Bahrami M, Abbasi M, Hariri H. The Relationship between Dignity Status and Quality of Life in Iranian Terminally Ill Patients with Cancer. Iran J Nurs Midwifery Res. 2017;22(3):178-183. doi:10.4103/1735-9066.208157
14. Chochinov HM, Hack T, Hassard T, Kristjanson LJ, McClement S, Harlos M. Dignity in the terminally ill: A cross-sectional, cohort study. Lancet. 2002;360(9350):2026-2030. doi:10.1016/S01406736(02)12022-8

15. Baillie L. Patient dignity in an acute hospital setting: A case study. Int J Nurs Stud. 2009;46(1):23-37. doi:10.1016/j.ijnurstu.2008. 08.003 .

16. Gastmans C. Dignity-enhancing nursing care: a foundational ethical framework. Nurs Ethics. 2013;20(2):142-149. doi:10.1177/ 0969733012473772

17. Papastavrou E, Efstathiou G, Andreou C. Nursing students' perceptions of patient dignity. Nurs Ethics. 2016;23(1):92-103. doi:10.1177/ 0969733014557136

18. Rehnsfeldt A, Lindwall L, Lohne V, et al. The meaning of dignity in nursing home care as seen by relatives. Nurs Ethics. 2014;21 (5):507-517. doi:10.1177/0969733013511358

19. Ebrahimi H, Torabizadeh C, Mohammadi E, Valizadeh S. Patients' perception of dignity in Iranian healthcare settings: a qualitative content analysis. J Med Ethics. 2012;38(12):723-728. doi:10.1136/ medethics-2011-100396

20. Naderi Z, Gholamzadeh S, Zarshenas L, Ebadi A. Hospitalized elder abuse in Iran: a qualitative study. BMC Geriatr. 2019;19(1):307. doi:10.1186/s12877-019-1331-8

21. Di Lorenzo R, Ferri P, Biffarella C, et al. Psychometric properties of the Patient Dignity Inventory in an acute psychiatric ward: an extension study of the preliminary validation. Neuropsychiatr Dis Treat. 2018;29(14):903-913. doi:10.2147/NDT.S153902.

22. Sanakova S, Cap J. Dignity from the nurses' and older patients' perspective: a qualitative literature review. Nurs Ethics. 2019;26 (5):1292-1309. doi:10.1177/0969733017747960.

23. Fernández-Sola C, Mmd C, Hernández-Padilla JM, Torres CJA, Jmm T, Granero-Molina J. Defining dignity in end-of-life care in the emergency department. Nurs Ethics. 2017;24(1):20-32. doi: $10.1177 / 0969733015604685$

24. Gilgun JF. Qualitative methods and the development of clinical assessment tools. Qual Health Res. 2004;14(7):1008-1019. doi:10.1177/1049732304266819

25. Holloway I, Galvin K. Qualitative research in nursing and healthcare. John Wiley \& Sons. 2016.

26. Elo S, Kääriäinen M, Pölkki. KO, Utriainen T, Utriainen K, Kyngäs H. Qualitative content analysis: A focus on trustworthiness. Sage Open. 2014;4(1):215824401452263. doi: $10.1177 / 2158244014522633$

27. Graneheim UH, Lundman B. Qualitative content analysis in nursing research: concepts, procedures and measures to achieve trustworthiness. Nurse Educ Today. 2004;24(2):105-112. doi:10.1016/j.nedt.2003.10.001

28. Lincoln YS, Guba EG. Naturalistic Inquiry. Newberry Park: CA: Sage; 1985.

29. Bylund CL, Makoul G. Empathic communication and gender in the physician-patient encounter. Patient Educ Couns. 2002;48 (3):207-216. doi:10.1016/s0738-3991(02)00173-8

30. Bendapudi NM, Berry LL, Frey KA, Parish JT, Rayburn WL. Patients' perspectives on ideal physician behaviors. Mayo Clin Proc. 2006;81(3):338-344. doi:10.4065/81.3.338

31. Shafati M, Zahedi MJ. Physician-patient relationship: ethnography of multiple patient visits at private offices of doctors. J Qual Res Health Sci. 2013;2:46-61.

32. Avizhgan M, Mirshahjafari E. Dignity in medicine: emphasis on dignity of end stage patients. Iran J Med Sci. 2012;11:1496-1510.

33. Zamanzadeh V, Rassouli M, Abbaszadeh A, Nikanfar A, Alavi-Majd $\mathrm{H}$, Ghahramanian A. Factors influencing communication between the patients with cancer and their nurses in oncology wards. Indian J Palliat Care. 2014;20(1):12. doi:10.4103/0973-1075.125549

34. Ferri P, Muzzalupo J, Di Lorenzo R. Patients' perception of dignity in an Italian general hospital: a cross-sectional analysis. BMC Health Serv Res. 2015;15:41. doi:10.1186/s12913-015-0704-8. 
35. Matiti MR, Trorey GM. Patients' expectations of the maintenance of their dignity. J Clin Nurs. 2008;17(20):2709-2717. doi:10.1111/ j.1365-2702.2008.02365

36. Joolaee S, Nikbakht-Nasrabadi A, Parsa-Yekta Z, Tschudin V, Mansouri I. An Iranian perspective on patients' rights. Nurs Ethics. 2006;13(5):488e502. doi:10.1191/0969733006nej895oa.

37. Woolhead G, Calnan M, Dieppe P, Tadd W. Dignity in older age: what do older people in the United Kingdom think? Age Ageing. 2004;33:165e70. doi:10.1093/ageing/afh045

38. Kennedy G. The importance of patient dignity in care at the end of life. Ulster Med J. 2016;85(1):45.

39. Henry LM, Rushton C, Beach MC, Faden R. Respect and dignity: a conceptual model for patients in the intensive care unit. Narrat Inq Bioeth. 2015;5(1):5A-14A. doi:10.1353/nib.2015.0007

40. Mohammadi F, Rakhshan M, Molazem Z, Zareh N, Gillespie M. Caregivers' perception of dignity in teenagers with autism spectrum disorder. Nurs Ethics. 2019;26(7-8):2035-2046. doi:10.1177/ 0969733018796679

41. Bagherian S, Sharif F, Zarshenas L, Torabizadeh C, Abbaszadeh A, Izadpanahi P. Cancer patients' perspectives on dignity in care. Nurs Ethics. 2020;27(1):127-140. doi:10.1177/0969733019845126.

42. Hall J, Mitchell M. Dignity and respect in midwifery education in the UK: a survey of Lead Midwives of Education. Nurse Educ Pract. 2016;21:9-15. doi:10.1016/j.nepr.2016.09.003

43. Baillie L, Matiti M. Dignity, equality and diversity: an exploration of how discriminatory behaviour of healthcare workers affects patient dignity. Divers Equal Health Care. 2013;10:5-12.

44. Lin Y-P, Watson R, Tsai Y-F. Dignity in care in the clinical setting: a narrative review. Nurs Ethics. 2013;20(2):168-177. doi:10.1177/ 0969733012458609

45. Christensen M, Hewitt-Taylor J. Patient empowerment: does it still occur in the ICU? Intensive Crit Care Nurs. 2007;23(3):156-161. doi:10.1016/j.iccn.2006.03.002

46. Iranmanesh S, Tirgari B, Cheraghi MA. Developing and testing a spiritual care questionnaire in the Iranian context. $J$ Relig Health. 2012;51(4):1104-1116. doi:10.1007/s10943-011-9458-8.

47. Albers G, Pasman HRW, Deliens L, de Vet HC, OnwuteakaPhilipsen BD. Does health status affect perceptions of factors influencing dignity at the end of life? J. Pain Symptom Manag. 2013;45:1030-1038. doi:10.1016/j.jpainsymman.2012.06.012

48. Rykkje LL, Eriksson K, Raholm MB. Spirituality and caring in old age and the significance of religion-a hermeneutical study from Norway. Scand J Caring Sc. 2013;27:275-284. doi:10.1111/j.14716712.2012.01028.x
49. Sarajärvi A, Haapamäki ML, Paavilainen E. Emotional and informational support for families during their child's illness. Int Nurs Rev. 2006;53(3):205-210. doi:10.1111/j.1466-7657.2006.00479.x

50. Mattila E, Kaunonen M, Aalto P, Åstedt-Kurki P. The method of nursing support in hospital and patients' and family members' experiences of the effectiveness of the support. Scand J Caring Sc. 2014;28 (2):305-314. doi: $10.1111 / \mathrm{scs} .12060$

51. Stahl D, Tomlinson T. Is there a right not to know? Nat. Rev Clin Oncol. 2017;14:259-260. doi:10.1038/nrclinonc.2017.47.

52. Dickert NW, Kass NE. Understanding respect: learning from patients. $J$ Med Ethics. 2009;35:419-423. doi:10.1136/jme.2008.027235

53. Levit LA, Balogh E, Nass SJ, Ganz P. Delivering High-Quality Cancer Care: Charting a New Course for a System in Crisis: Charting a New Course for a System in Crisis, Patient-Centered Communication and Shared Decision Making. Washington, DC: National Academies Press; 2013.

54. Hosseini FA, Momennasab M, Yektatalab S, Zareiyan A. Patients' perception of dignity in Iranian general hospital settings. Nurs Ethics. 2019;26(6):1777-1790. doi:10.1177/0969733018772078.

55. Babaei S, Taleghani F, Kayvanara M. Compassionate behaviours of clinical nurses in Iran: an ethnographic study. Int Nurs Rev. 2016;63:388-394. doi:10.1111/inr.12296

56. Kornhaber R, Walsh K, Duff J, Walker K. Enhancing adult therapeutic interpersonal relationships in the acute health care setting: an integrative review. J Multidiscip Healthc. 2016;9:537. doi:10.2147/ JMDH.S116957

57. Fan SY, Lin IM, Hsieh JG, Chang CJ. Psychosocial care provided by physicians and nurses in palliative care: A mixed methods study. $J$ Pain Symptom Manag. 2017;53(2):216-223. doi:10.1016/j. jpainsymman.2016.08.019.

58. Davidson JE. Family-centered care: meeting the needs of patients' families and helping families adapt to critical illness. Crit Care Nurse. 2009;29:28-34. doi:10.4037/ccn2009611.

59. Avci IA, Kumcagiz H. Marital adjustment and loneliness status of women with mastectomy and husband's reactions. Asian Pac $J$ Cancer Prev. 2011;12(2):453-459.

60. Chaudhary AS. Dignity at the Termination of Life Care: an Integrative View. Palliat Med Care Int J. 2019;2(5):555598. doi:10.19080/PMCIJ.2019.02.555598

61. Chochinov HM. Dignity-conserving care - a new model for palliative care: helping the patient feel valued. JAMA. 2002;287 (17):2253-2260. doi:10.1001/jama.287.17.2253
Journal of Multidisciplinary Healthcare

\section{Publish your work in this journal}

The Journal of Multidisciplinary Healthcare is an international, peerreviewed open-access journal that aims to represent and publish research in healthcare areas delivered by practitioners of different disciplines. This includes studies and reviews conducted by multidisciplinary teams as well as research which evaluates the results or conduct of such teams or healthcare processes in general. The journal covers a very wide range of areas and welcomes submissions from practitioners at all levels, from all over the world. The manuscript management system is completely online and includes a very quick and fair peer-review system. Visit http://www.dovepress.com/testimonials. php to read real quotes from published authors. 